\title{
Present challenges in hadrontherapy techniques
}

\author{
U. Amaldi ${ }^{1,2}$ and S. Braccini ${ }^{3, a}$ \\ 1 University of Milano-Bicocca - Piazza della Scienza 3, I-20126 Milano, Italy \\ 2 TERA Foundation - Via Puccini 11, Novara, Italy \\ 3 Albert Einstein Centre for Fundamental Physics, Laboratory for High Energy Physics (LHEP), University of Bern \\ Sidlerstrasse 5, CH-3012 Bern, Switzerland
}

Received: 9 May 2011

Published online: 27 July 2011 - C Società Italiana di Fisica / Springer-Verlag 2011

\begin{abstract}
Hadrontherapy is a high-precision technique in cancer radiation therapy, which allows obtaining a superior conformal treatment with respect to photons used in conventional radiation therapy. To reach this ambitious goal without reducing the patient throughput needed in a hospital-based environment, the physical and radiobiological properties of charged hadrons, protons and carbon ions in particular, have to be exploited at best, making use of the most modern technologies issued from research in nuclear and particle physics. In the present days, we are assisting to a continuous technological challenge, leading to the conception and to the development of innovative methods and instruments. In this paper, the most relevant challenges in dose delivery systems, gantries, imaging, quality assurance and particle accelerators are reviewed.
\end{abstract}

\section{Generalities on hadrontherapy}

Hadrontherapy —often also denominated "particle therapy" — is a collective word used to indicate the treatment of tumours through external irradiation by means of accelerated hadronic particles. Several kinds of particles have been and are the subject of intensive clinical and radiobiological studies: neutrons, protons, pions, antiprotons, helium, lithium, boron, carbon and oxygen ions. Among all these possibilities, only two of them — protons and carbon ionsare nowadays used in clinical practice and represent the focus of an ongoing remarkable scientific and technological development. For this reason, only proton and carbon ion therapies are discussed in this paper.

Protons and carbon ions are more advantageous with respect to X-rays mainly because of three reasons, two of which pertain to physics and one to radiation biophysics. The release of energy of charged hadrons along their path inside the patient's body is characterized by a large deposit localized in the last few millimetres at the end of their range, in the so-called Bragg peak region. Here they produce most of the damage to the cells, while sparing both traversed and deeper located healthy tissues. Moreover, charged hadrons penetrate the patient with minimal diffusion and, using their electric charge, few millimetre FWHM "pencil beams" of variable penetration depth can be precisely guided towards any part of the tumour. Finally, the ionization properties of light ions are such that they deposit in a traversed cell much larger energy in the Bragg peak region with respect to protons having the same range. For carbon ions, a factor 24 more energy is deposited and the produced ionization column is therefore so dense to be able to induce direct multiple strand brakes in the DNA, thus leading to damages, which are often non-repairable by the usual cellular mechanisms. This effect is quantified by an enhancement of the Radio Biological Effectiveness (RBE) and opens the way to the treatment of tumours, which are resistant to X-rays and protons at the doses prescribed by standard medical protocols.

In connection with this argument, it has to be stressed that hypoxic tissues are known to be less radiosensitive than oxygenated ones, so that the presence or absence of oxygen within cells has a strong influence on the biological effects of radiation. This effect - which is expressed in terms of Oxygen Enhancement Ratio (OER) - is very much dependent on the Linear Energy Transfer (LET). For low LET radiation, such as X-rays or protons, hypoxia represents a serious limitation factor to the effectiveness of the treatment. For high LET, this effect is reduced and carbon ions represent a powerful tool for the treatment of hypoxic radio resistant tumours [1].

\footnotetext{
a e-mail: saverio.braccini@cern.ch
} 


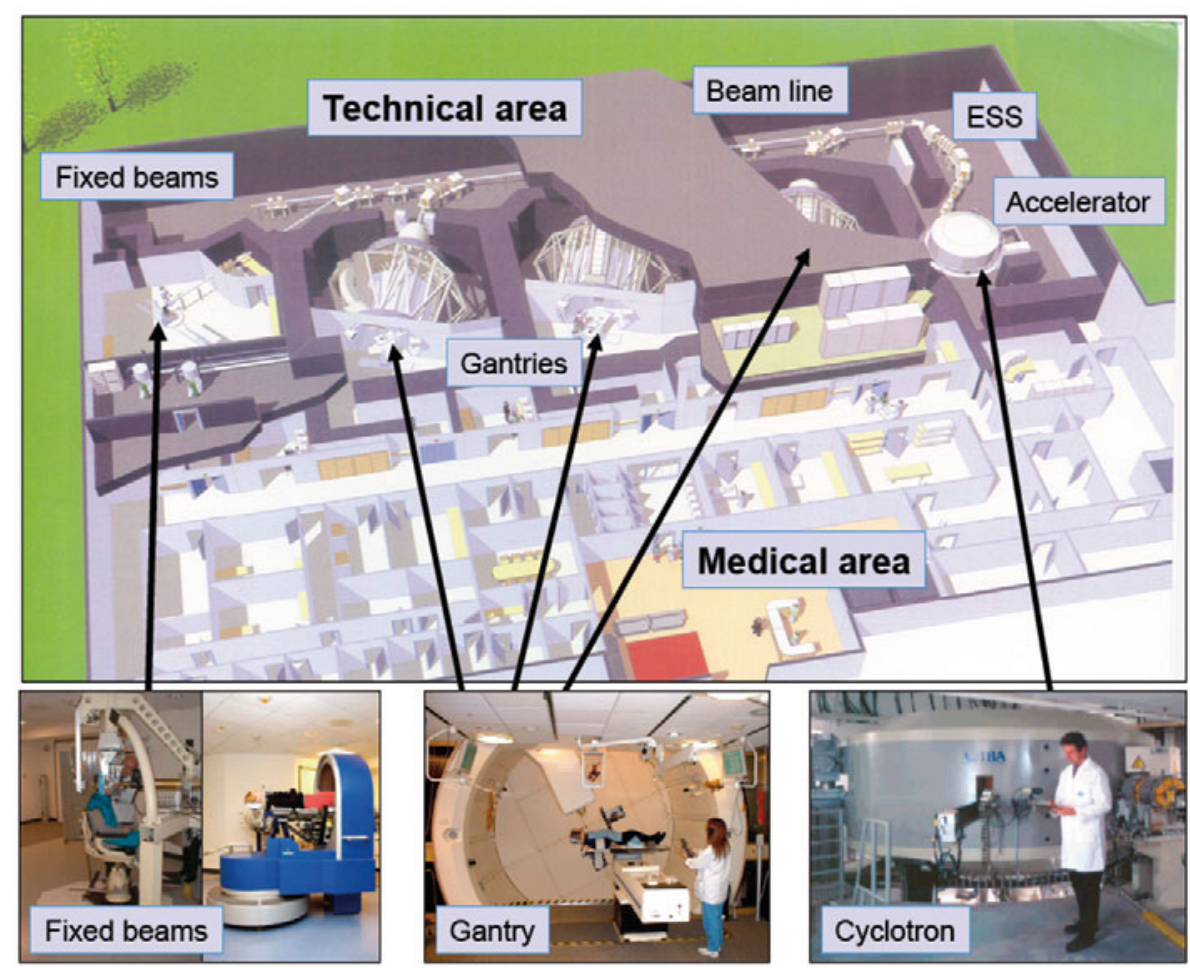

Fig. 1. General layout of a proton therapy centre featuring one accelerator, three treatment rooms with rotating gantries, one treatment room with fixed horizontal beams and one room for research activities. The example reported here is based on a system commercialized by the company IBA (Belgium). The Energy Selection System (ESS) is present only with cyclotrons and consists on a long magnetic channel, equipped with movable absorbers and slits, needed to vary the energy. (Courtesy IBA.)

Molecular imaging is expected to play an important role in treatment planning in the near future [2] and, in particular, the detection of hypoxic tumour tissues by means of Positron Emission Tomography (PET) radiotracers represents a potential tool to tailor at best the therapeutical strategy.

In order to treat deep-seated tumours, maximum depths of the order of $25 \mathrm{~cm}$ in soft tissues have to be reached. This directly translates into the maximum energy of proton and carbon ion beams which has be employed: $200 \mathrm{MeV}$ and $4500 \mathrm{MeV}$ (i.e. $375 \mathrm{MeV} /$ u), respectively. As far as beam currents are concerned, the limit is set by the amount of dose to be delivered to the tissues, typically 2 Gy per litre per minute. This translates into beam currents on target of the order of $1 \mathrm{nA}$ and $0.1 \mathrm{nA}$ for protons and carbon ions, respectively.

The maximum energy and current determine the main characteristics of the accelerator: $4-5$ metre diameter cyclotrons, both at room temperature and superconducting, and 6-8 metre diameter synchrotrons are today in use for proton therapy while for carbon ion therapy only 20-25 metre diameter synchrotrons are commercially available.

As presented in fig. 1, a modern hadrontherapy centre is based on a complex facility in which the accelerator is connected to several treatment rooms by means of beam transport lines. The treatment rooms are equipped with fix beams - usually horizontal but vertical and $45^{\circ}$ are also in use - and/or rotating gantries, which, for proton therapy, are about $10 \mathrm{~m}$ high, 100 tons heavy structures supporting a set of magnets, so that the patient can be irradiated from any direction, exactly like in conventional X-ray radiation therapy.

The first idea of using accelerated protons and ions in cancer radiation therapy dates back to 1946 when R. Wilson wrote a very illuminating seminal paper [3] in which all the basic principles and potentialities of this discipline are stated and remarkably discussed, especially if one considers the fact that precise imaging techniques and enough powerful accelerators were almost a dream at that time. It is interesting to remark that Wilson discussed proton beams, but mentioned also helium and carbon ions.

The choice of carbon ions was made at the beginning of the nineties and today it is often asked whether other ions, different from protons and carbon, could be beneficial. The answer is clear for ions heavier than carbon, which, being characterized by a too high LET in the entrance channel and by a too large fragmentation, cannot be considered as good candidates for cancer therapy. The clinical treatments performed in Berkeley in the seventies with Ne ions clearly demonstrated that undesirable effects are produced in the traversed and downstream healthy tissues [4]. On the other hand, the use of ions lighter than carbon — such as helium, lithium and boron - present some potential advantages [5] and are matter of scientific debate. With respect to protons, they have less lateral scattering and present a sharper 
distal edge. When compared to carbon ions, they have less fragmentation and a smaller LET in the entrance channel, which is particularly important for shallow tumours. Moreover, from a technical point of view, they need smaller accelerators.

\section{Present status of hadrontherapy centres}

The first hadrontherapy treatments took place with proton beams in Berkeley [6] in 1954, followed by Uppsala in 1957. This pioneering work opened the way to the intense activity performed at the Harvard cyclotron [7] where physicists and radiation oncologists worked together for many decades on three main clinical studies: neurosurgery for intracranial lesions (3687 patients), eye tumours (2979 patients) and head-neck tumours (2449 patients). The illuminating results obtained by the Harvard group represented the basis for many of the successive clinical and technical developments.

A fundamental milestone was accomplished in 1990 when the first patient was treated at the Loma Linda University Medical Center in California, the first hospital based proton therapy centre [8]. This facility featured the first "corkscrew"-type rotating gantries [9] designed for routine treatment. It has to be remarked that, up to this moment, all the hadrontherapy facilities were based on existing particle accelerators designed for fundamental research, often sharing human resources and beam time with other activities. Moreover, some of these centres made use of low energy - about $70 \mathrm{MeV}$ - cyclotrons, in which only the treatment of ocular pathologies was possible. About 14000 patients have been irradiated, mainly with protons (10243) and helium ions (2054), in the about ten centres, which had all been built in nuclear or particle physics laboratories and are now closed [10].

In the last twenty years, from being practiced only in specialized research laboratories, proton therapy is becoming a widely recognized clinical modality in oncology. By the end of 2010, more than 80000 patients have been treated by proton therapy worldwide, very often affected by pathologies located near critical structures, the so-called organs at risk (OAR). It is important to remark the importance of proton therapy for paediatric patients, for whom the irradiation of critical organs may lead to severe permanent consequences on the quality of life and to possible induction of secondary cancers [11].

As reported in tables 1 and 2, many hadrontherapy centres are nowadays in operation, under construction or in a phase of advanced project and more than twenty new hospital-based facilities are expected to be operational in the next five years, mostly located in USA, Europe and Japan. It is worth stressing the essential contribution to this development given by the main commercial companies active in this field: Hitachi (Japan), IBA (Belgium), Mitsubishi (Japan), Optivus (USA), Siemens (Germany) and Varian/Accel (USA/Germany).

It is also interesting to remark that more and more centres are "dual", in the sense that they feature not only protons but also carbon ions, as discussed in the next section.

\section{Therapy with carbon ions}

While proton therapy is nowadays considered an established clinical modality, carbon ion therapy is still on its way to become a commonly accepted treatment option. Due to its specificity and to the complex radiobiological models essential for treatment planning, carbon ion therapy is nowadays facing a challenging phase of intense technical research and clinical trials.

Since the construction of the Heavy Ion Medical Accelerator in Chiba (HIMAC), which treated the first patient in 1994, Japan is the most advanced country in carbon ion therapy. By the end of 2009, about 5000 patients have been treated and many radio resistant tumours have been shown to be controllable.

In Europe, treatments started at the "pilot project" for carbon ion therapy at GSI in Germany in 1997. Since then, about 400 patents have been treated and this project lead to the construction of the first European hospital-based centre in Heidelberg (HIT). This new centre features a gigantic 600 tons, 25 metre long carbon ion gantry (see fig. 5, left) - the only one constructed so far - and treated the first patient in November 2009.

In 1995 one of us (UA) proposed (in collaboration with Mainard Regler, promoter of the MedAustron project) to the CERN management to initiate the Proton Ion Medical Machine Study (PIMMS), centred on the design of a synchrotron and a system of beam lines optimized for the treatment of deep seated tumours with collimated beams of carbon ions, protons and other light ions. From 1996 to 2000 the study was carried out under the direction of Phil Bryant with the help of many part-time staff members of CERN and with essential contributions from TERA (Italy), Med-AUSTRON (Austria) and Oncology 2000 (Czech Republic) [12]. From the PIMMS study, the TERA design of the Centro Nazionale di Adroterapia Oncologica (CNAO) has been completed and passed in 2004 to the CNAO Foundation, which — in collaboration with INFN - has completed its construction in 2010 in Pavia. The CNAO will be the second hospital-based centre for proton and carbon ion therapy in Europe. Two more centres are under construction in Germany, in Marburg and Kiel, by the company Siemens, which has obtained the know-how and the patents from GSI. MedAustron in Austria has recently acquired the drawings of CNAO to build in Wiener 
Table 1. Hospital-based hadrontherapy facilities in operation at the end of 2010 [10].

\begin{tabular}{|c|c|c|c|c|c|c|c|}
\hline Centre & Country & $\begin{array}{l}\text { Part. } \\
\text { acc. }\end{array}$ & $\begin{array}{c}\text { Max. } \\
\text { clinical } \\
\text { energy } \\
(\mathrm{MeV})\end{array}$ & $\begin{array}{c}\text { Beam } \\
\text { direction }^{(a)}\end{array}$ & $\begin{array}{l}\text { Start } \\
\text { of } \\
\text { treat. }\end{array}$ & $\begin{array}{l}\text { Total } \\
\text { treated } \\
\text { patients }\end{array}$ & $\begin{array}{c}\text { Date of } \\
\text { total }\end{array}$ \\
\hline ITEP, Moscow & Russia & $\mathrm{p}, \mathrm{S}$ & 250 & $\mathrm{H}$ & 1969 & 4226 & Dec-10 \\
\hline St.Petersburg & Russia & $\mathrm{p}, \mathrm{SC}$ & 1000 & $\mathrm{H}$ & 1975 & 1362 & Dec-10 \\
\hline $\mathrm{PSI}^{(\mathrm{b})}$ & Switzerland & $\mathrm{p}, \mathrm{C}$ & 72 & $\mathrm{H}$ & 1984 & 5458 & Oct-10 \\
\hline Dubna $^{(\mathrm{c})}$ & Russia & $\mathrm{p}, \mathrm{SC}$ & 200 & $\mathrm{H}$ & 1999 & 720 & Dec-10 \\
\hline Uppsala & Sweden & $\mathrm{p}, \mathrm{C}$ & 200 & $\mathrm{H}$ & 1989 & 929 & Dec-08 \\
\hline Clatterbridge $^{(\mathrm{b})}$ & England & $\mathrm{p}, \mathrm{C}$ & 62 & $\mathrm{H}$ & 1989 & 2021 & Dec-10 \\
\hline Loma Linda & USA & $\mathrm{p}, \mathrm{S}$ & 250 & $3 \mathrm{G}, \mathrm{H}$ & 1990 & 15000 & Jan-11 \\
\hline Nice $^{(b)}$ & France & $\mathrm{p}, \mathrm{C}$ & 65 & $\mathrm{H}$ & 1991 & 4209 & Dec-10 \\
\hline Orsay $^{(\mathrm{d})}$ & France & $\mathrm{p}, \mathrm{C}$ & 230 & $\mathrm{G}, \mathrm{H}$ & 1991 & 5216 & Dec-10 \\
\hline iThemba Labs & South Africa & $\mathrm{p}, \mathrm{C}$ & 200 & $\mathrm{H}$ & 1993 & 511 & Dec-09 \\
\hline $\operatorname{MPRI}(2)$ & USA & $\mathrm{p}, \mathrm{C}$ & 230 & $2 \mathrm{G}, \mathrm{H}$ & 2004 & 1145 & Dec-10 \\
\hline $\mathrm{UCSF}^{(\mathrm{b})}$ & USA & $\mathrm{p}, \mathrm{C}$ & 60 & $\mathrm{H}$ & 1994 & 1285 & Dec-10 \\
\hline HIMAC & Japan & $\mathrm{C}, \mathrm{S}$ & $800 / u$ & $\mathrm{H}, \mathrm{V}$ & 1994 & 5497 & Aug-10 \\
\hline TRIUMF $^{(b)}$ & Canada & $\mathrm{p}, \mathrm{C}$ & 72 & $\mathrm{H}$ & 1995 & 152 & Dec-10 \\
\hline $\mathrm{PSI}^{(\mathrm{e})}$ & Switzerland & $\mathrm{p}, \mathrm{C}$ & 250 & $\mathrm{G}$ & 1996 & 704 & Dec-10 \\
\hline GSI & Germany & $\mathrm{C}, \mathrm{S}$ & $430 / u$ & $\mathrm{H}$ & 1997 & 440 & Dec-10 \\
\hline HZB (HMI), Berlin ${ }^{(\mathrm{b})}$ & Germany & $\mathrm{p}, \mathrm{C}$ & 72 & $\mathrm{H}$ & 1998 & 1660 & Dec-10 \\
\hline NCC, Kashiwa & Japan & $\mathrm{p}, \mathrm{C}$ & 235 & $2 \mathrm{G}, \mathrm{H}$ & 1998 & 772 & Dec-10 \\
\hline HIBMC, Hyogo & Japan & $\mathrm{p}, \mathrm{S}$ & 230 & $2 \mathrm{G}, \mathrm{H}$ & 2001 & 2382 & Nov-09 \\
\hline HIBMC, Hyogo & Japan & $\mathrm{C}, \mathrm{S}$ & $320 / u$ & $\mathrm{H}, \mathrm{V}, 45^{\circ}$ & 2002 & 638 & Nov-09 \\
\hline PMRC(2), Tsukuba & Japan & $\mathrm{p}, \mathrm{S}$ & 250 & $2 \mathrm{G}, \mathrm{H}$ & 2001 & 1849 & Dec-10 \\
\hline NPTC, MGH, Boston & USA & $\mathrm{p}, \mathrm{C}$ & 235 & $2 \mathrm{G}, \mathrm{H}$ & 2001 & 4967 & Dec-10 \\
\hline INFN-LNS,Catania $^{(\mathrm{b})}$ & Italy & $\mathrm{p}, \mathrm{C}$ & 60 & $\mathrm{H}$ & 2002 & 174 & Mar-09 \\
\hline Shizuoka & Japan & $\mathrm{p}, \mathrm{S}$ & 235 & $2 \mathrm{G}, \mathrm{H}$ & 2003 & 986 & Dec-10 \\
\hline WERC,Tsuruga & Japan & $\mathrm{p}, \mathrm{S}$ & 200 & $\mathrm{H}, \mathrm{V}$ & 2002 & 62 & Dec-09 \\
\hline WPTC, Zibo & China & $\mathrm{p}, \mathrm{C}$ & 230 & $3 \mathrm{G}, \mathrm{H}$ & 2004 & 1078 & Dec-10 \\
\hline $\begin{array}{l}\text { MD Anderson Cancer Center, } \\
\text { Houston }^{(\mathrm{f})}\end{array}$ & USA & $\mathrm{p}, \mathrm{S}$ & 250 & $3 \mathrm{G}, \mathrm{H}$ & 2006 & 1700 & Dec-09 \\
\hline UFPTI, Jacksonville & USA & $\mathrm{p}, \mathrm{C}$ & 230 & $3 \mathrm{G}, \mathrm{H}$ & 2006 & 2679 & Dec-10 \\
\hline NCC, IIsan & South Korea & $\mathrm{p}, \mathrm{C}$ & 230 & $2 \mathrm{G}, \mathrm{H}$ & 2007 & 648 & Dec-10 \\
\hline RPTC, Munich $^{(\mathrm{g})}$ & Germany & $\mathrm{p}, \mathrm{C}$ & 250 & $4 \mathrm{G}, \mathrm{H}$ & 2009 & 446 & Dec-10 \\
\hline ProCure, Oklahoma & USA & $\mathrm{p}, \mathrm{C}$ & 230 & $\begin{array}{c}\mathrm{G}, \mathrm{H}, 2 \\
\mathrm{H} / 60^{\circ}\end{array}$ & 2009 & 21 & Dec-09 \\
\hline HIT, Heidelberg & Germany & $\mathrm{p}, \mathrm{S}$ & 250 & $2 \mathrm{H}, \mathrm{G}$ & 2009 & $\begin{array}{r}\text { Treatment } \\
\text { started }\end{array}$ & Nov-09 \\
\hline HIT, Heidelberg & Germany & $\mathrm{C}, \mathrm{S}$ & $430 / u$ & $2 \mathrm{H}, \mathrm{G}$ & 2009 & $\begin{array}{r}\text { Treatment } \\
\text { started }\end{array}$ & Nov-09 \\
\hline $\begin{array}{l}\text { U. Pennsylvania, } \\
\text { Philadelphia }\end{array}$ & USA & $\mathrm{p}, \mathrm{C}$ & 230 & $4 \mathrm{G}, \mathrm{H}$ & 2010 & 150 & Dec-10 \\
\hline GHMC, Gunma & Japan & $\mathrm{C}, \mathrm{S}$ & $400 / u$ & $3 \mathrm{H}, \mathrm{V}$ & 2010 & $\begin{array}{r}\text { Treatment } \\
\text { started }\end{array}$ & Mar-10 \\
\hline IMPCAS, Langzou & China & $\mathrm{C}, \mathrm{S}$ & $400 / u$ & $1 \mathrm{H}$ & 2009 & 126 & Dec-10 \\
\hline CDH, Warrenville & USA & $\mathrm{p}, \mathrm{C}$ & 230 & $\begin{array}{c}\mathrm{G}, \mathrm{H} \\
2 \mathrm{H} / 60\end{array}$ & 2010 & $\begin{array}{r}\text { Treatment } \\
\text { started }\end{array}$ & Oct-10 \\
\hline IFJ PAN, Krakow ${ }^{(\mathrm{b})}$ & Poland & $\mathrm{p}, \mathrm{C}$ & 60 & $\mathrm{H}$ & 2011 & 9 & Apr-11 \\
\hline Total protons & & & & & & 68144 & \\
\hline Total C-ions & & & & & & 6701 & \\
\hline Total & & & & & & 74845 & \\
\hline
\end{tabular}

(a) Horizontal (H), vertical (V), gantry (G), inclined (ex. $\left.45^{\circ}\right)$.

(b) Ocular tumours only.

(c) Degraded beam.

(d) 3676 ocular tumours; previously SC; new cyclotron and gantry since Nov-10.

(e) Degraded beam from 1996 to 2006; dedicated $250 \mathrm{MeV}$ proton beam from 2007. Scanning beam only.

(f) With spread and scanning beams (since 2008).

(g) Scanning beam only 
Table 2. Hospital-based hadrontherapy facilities in planning or under construction at the end of 2010 (main source [10]).

\begin{tabular}{|c|c|c|c|c|c|c|}
\hline Location & Country & Particle & $\begin{array}{l}\text { Max. energy } \\
(\mathrm{MeV}) \text { - acc. }\end{array}$ & Beams $^{(a)}$ & Rooms & $\begin{array}{c}\text { Foreseen start } \\
\text { date }\end{array}$ \\
\hline PSI, Villigen & Switzerland & $\mathrm{p}$ & $\begin{array}{c}250 \\
\text { SC cyclotron }\end{array}$ & $\begin{array}{c}1 \mathrm{G} \text { additional } \\
\text { to } 1 \mathrm{G}, 1 \mathrm{H}\end{array}$ & 3 & 2011 (Gantry2) \\
\hline WPE, Essen & Germany & $\mathrm{p}$ & $\begin{array}{c}230 \\
\text { cyclotron }\end{array}$ & $3 \mathrm{G}, 1 \mathrm{H}$ & 43 & 2011 \\
\hline CNAO, Pavia & Italy & $\mathrm{p}, \mathrm{C}$ & $\begin{array}{c}430 / u \\
\text { synchrotron }\end{array}$ & $2 \mathrm{H}, 1 \mathrm{H}+\mathrm{V}$ & 3 & 2011 \\
\hline PTC, Marburg & Germany & $\mathrm{p}, \mathrm{C}$ & $\begin{array}{c}430 / u \\
\text { synchrotron }\end{array}$ & $\begin{array}{l}3 \mathrm{H} \\
1 \mathrm{OB}\end{array}$ & 4 & 2011 \\
\hline $\begin{array}{l}\text { Chang Gung } \\
\text { Memorial Hospital }\end{array}$ & Taiwan & $\mathrm{p}$ & $\begin{array}{c}235 \\
\text { cyclotron }\end{array}$ & $\begin{array}{c}4 \mathrm{G} \\
1 \mathrm{H} \text { (research) }\end{array}$ & 4 & 2011 \\
\hline PTC, Fukushima & Japan & $\mathrm{p}$ & $\begin{array}{c}230 \\
\text { cyclotron }\end{array}$ & $2 \mathrm{G}, \mathrm{H}$ & 3 & 2011 \\
\hline ProCure, Chicago & USA & $\mathrm{p}$ & $\begin{array}{c}230 \\
\text { cyclotron }\end{array}$ & $2 \mathrm{H}, 2 \mathrm{H}+\mathrm{V}$ & 4 & 2011 \\
\hline $\begin{array}{l}\text { HUPBTC, } \\
\text { Hampton }\end{array}$ & USA & $\mathrm{p}$ & $\begin{array}{c}230 \\
\text { cyclotron }\end{array}$ & $4 \mathrm{G}, 1 \mathrm{H}$ & 5 & 2011 \\
\hline $\begin{array}{l}\text { PMHPTC, } \\
\text { Protvino }\end{array}$ & Russia & $\mathrm{p}$ & $\begin{array}{c}250 \\
\text { cyclotron }\end{array}$ & $1 \mathrm{H}$ & 1 & 2011 \\
\hline $\begin{array}{l}\text { Medipolis, } \\
\text { Kagoshima }\end{array}$ & Japan & $\mathrm{p}$ & $\begin{array}{c}250 \\
\text { synchrotron }\end{array}$ & $3 \mathrm{G}$ & 3 & 2011 \\
\hline NRoCK, Kiel & Germany & $\mathrm{p}, \mathrm{C}$ & $\begin{array}{c}430 / u \\
\text { synchrotron }\end{array}$ & $\begin{array}{c}1 \mathrm{H}, 1 \mathrm{~V}+\mathrm{OB}, \\
1 \mathrm{H}+\mathrm{V}\end{array}$ & 3 & 2012 \\
\hline NIPTRC, Chicago & USA & $\mathrm{p}$ & $\begin{array}{c}250 \\
\text { SC cyclotron }\end{array}$ & $\begin{array}{c}2 \mathrm{G} \\
2 \mathrm{H} \\
1 \mathrm{H}(\text { research })\end{array}$ & 4 & 2012 \\
\hline $\begin{array}{l}\text { Barnes Jewish, St. } \\
\text { Louis }\end{array}$ & USA & $\mathrm{p}$ & $\begin{array}{c}250 \\
\text { single room SC } \\
\text { synchrocyclotron }\end{array}$ & $1 \mathrm{G}$ & 1 & 2012 \\
\hline PTC & $\begin{array}{l}\text { Czech } \\
\text { Republic }\end{array}$ & $\mathrm{p}$ & $\begin{array}{c}230 \\
\text { cyclotron }\end{array}$ & $3 \mathrm{G}, \mathrm{H}$ & 4 & 2013 \\
\hline HITFil, Lanzhou & China & $\mathrm{C}$ & $\begin{array}{c}400 / u \\
\text { synchrotron }\end{array}$ & $4 \mathrm{H}, \mathrm{V}, \mathrm{OB}$ & 4 & 2013 \\
\hline ATreP, Trento & Italy & $\mathrm{p}$ & $\begin{array}{c}230 \\
\text { cyclotron }\end{array}$ & $1 \mathrm{G}, 1 \mathrm{H}$ & 2 & 2013 \\
\hline $\begin{array}{l}\text { Skandionkliniken, } \\
\text { Uppsala }\end{array}$ & Sweden & $\mathrm{p}$ & $\begin{array}{c}250 \\
\text { Cyclotron }\end{array}$ & $2 \mathrm{G}$ & 2 & 2013 \\
\hline $\begin{array}{l}\text { Scripps Proton } \\
\text { Therapy Center, } \\
\text { San Diego }\end{array}$ & USA & $\mathrm{p}$ & $\begin{array}{c}250 \\
\text { SC cyclotron }\end{array}$ & $\begin{array}{l}3 \mathrm{G} \\
2 \mathrm{H}\end{array}$ & 5 & 2013 \\
\hline $\begin{array}{l}\text { Med-AUSTRON, } \\
\text { Wiener Neustadt }\end{array}$ & Austria & $\mathrm{p}, \mathrm{C}$ & $\begin{array}{c}400 / u \\
\text { synchrotron }\end{array}$ & $\begin{array}{c}1 \mathrm{G} \text { (p only), } \\
1 \mathrm{~V} \\
1 \mathrm{~V}+\mathrm{H}\end{array}$ & 3 & 2014 \\
\hline iThemba Labs & South Africa & $\mathrm{p}$ & $\begin{array}{c}230 \\
\text { cyclotron }\end{array}$ & $1 \mathrm{G}, 2 \mathrm{H}$ & 3 & $?$ \\
\hline RPTC, Koeln & Germany & $\mathrm{p}$ & $\begin{array}{c}250 \\
\text { SC cyclotron }\end{array}$ & $4 \mathrm{G}, 1 \mathrm{H}$ & 5 & $?$ \\
\hline CCSR, Bratislava & $\begin{array}{l}\text { Slovak } \\
\text { Republic }\end{array}$ & $\mathrm{p}$ & $\begin{array}{c}72 \\
\text { cyclotron }\end{array}$ & $1 \mathrm{H}$ & 1 & $?$ \\
\hline СМНРТС & $\begin{array}{l}\text { Slovak } \\
\text { Republic }\end{array}$ & $\mathrm{p}$ & $\begin{array}{c}250 \\
\text { synchrotron }\end{array}$ & $1 \mathrm{H}$ & 1 & $?$ \\
\hline SJFH, Beijing & China & $\mathrm{p}$ & 230 cyclotron & $1 \mathrm{G}, 1 \mathrm{H}$ & 2 & $?$ \\
\hline Shanghai & China & $\mathrm{p}, \mathrm{C}$ & $\begin{array}{c}430 / u \\
\text { synchrotron }\end{array}$ & $\begin{array}{c}1 \mathrm{H}, 1 \mathrm{~V}+\mathrm{OB}, \\
1 \mathrm{H}+\mathrm{V}\end{array}$ & 3 & $?$ \\
\hline ETOILE, Lyon & France & $\mathrm{p}, \mathrm{C}$ & $?$ & $?$ & $?$ & $?$ \\
\hline
\end{tabular}

(a) Horizontal $(\mathrm{H}), 90^{\circ}$ vertical $(\mathrm{V}), 45^{\circ}$ oblique $(\mathrm{OB})$, rotating gantry $(\mathrm{G})$. 


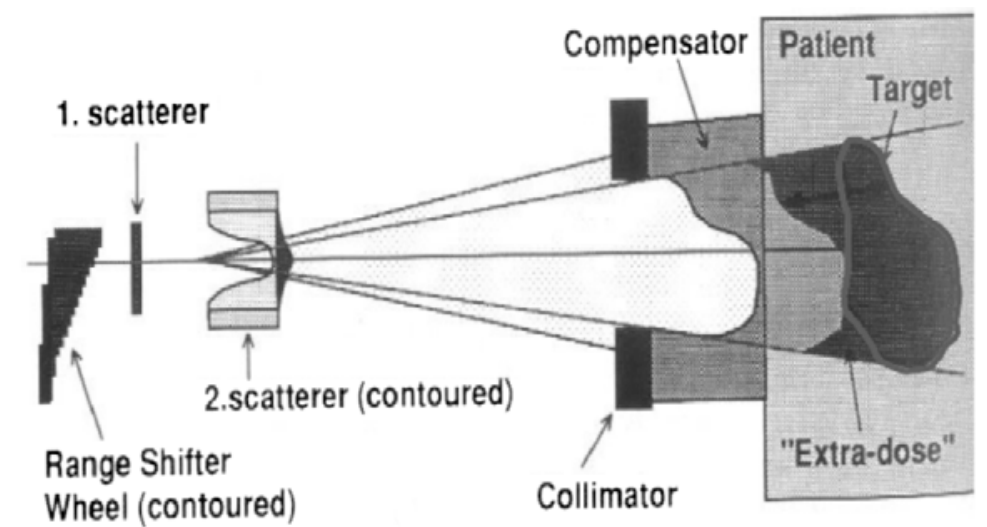

Fig. 2. In "passive spreading", the beam is widened and flattened by means of scatterers and adapted to the volume to be irradiated by means of personalized collimators and compensators. Different penetration depths are superimposed by means of a range shifter to obtain the Spread Out Bragg Peak (SOBP) covering the tumour.

Neustadt a dual centre. In France, Etoile in Lyon is now in the tendering phase while IBA is developing an innovative superconducting cyclotron (see later) for carbon ion therapy in the framework of the Archade Project in Caen (France).

Thus, in a few years, several hospital based centres for carbon ion therapy will be operational and will produce, through Phase III trials, the necessary knowledge needed to apply this modality only to the tumours which need it.

For about fifteen years, hadrontherapy is facing a deep change which is bringing a relatively small scientific community into a much larger multidisciplinary contest in which medicine, physics, biology, engineering, law, management and finance came together and play essential and complementary roles. The large size of these projects, costing 100-200 million Euro, has a big impact not only on the scientific and technological side but also on the financial, logistic and management aspects. Needles to say that in the construction of a hadrontherapy centre all the details have to be carefully evaluated since the very beginning by a solid multi-competence project team capable of facing the unavoidable problems and compromises.

Two main forces — not always pointing towards the same direction - are driving the developments of this discipline. On the one hand, to be competitive with the continuously increasing performances of conventional radiation therapy, innovative tools and techniques are needed to exploit at best the higher potential of hadron beams. On the other hand, to be able to offer this treatment modality to a large number of patients with cost-effective throughput, the cost, the size and the complexity of the equipment have to be reduced. To face these challenges, many scientific and technological developments are ongoing and new ideas are appearing at the horizon.

\section{Challenges in dose delivery systems}

The dose delivery system represents a key issue in the treatment process since it allows the transformation of the beam coming out from the accelerator into a clinical three-dimensional dose distribution, which has to comply with the medical prescription.

Up to the present and in almost all the centres, the "passive spreading" method — presented in fig. 2 - is used. Although relatively simple, this method requires the construction of personalized "compensators" and, often, "collimators" and does not allow exploiting at best the ballistic properties of charged hadron beams. In particular, extra doses are produced at the edges of the tumour.

To avoid this, "active" delivery systems are needed. Two innovative techniques have been developed at PSI (protons) and GSI (carbon ions) to "paint" the tumour by means of a small "pencil beam" driven by magnetic forces and without the use of any passive device, as presented in fig. 3.

The PSI "spot scanning" [13] technique and the GSI "raster scanning" technique [14] provide very conformal dose distributions. By the superposition of non-uniform dose distributions coming from many directions, they allow very complex treatments by Intensity Modulated Particle Therapy (IMPT). Scanning techniques are nowadays becoming mature and commercial companies are offering this modality, often in parallel with the standard passive spreading.

To fully exploit the potentialities of scanning and IMPT, a new dedicated gantry is under commissioning at PSI since the beginning of 2011. The "Gantry 2" [15] scans the tumour with parallel beams in a two-dimensional surface and rotates only by $180^{\circ}$ to allow an easier access to the patient with a more compact structure. The possibility to use $\mathrm{X}$-rays parallel to the proton beam and passing through a special aperture in the $90^{\circ}$ magnet is foreseen to optimize the treatment of moving organs. 


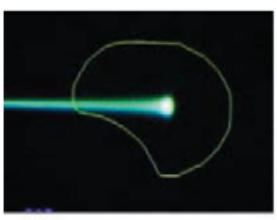

Single beam...

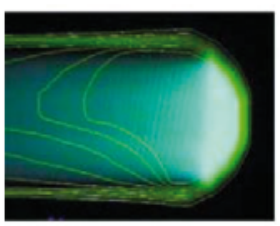

+ scanning in depth

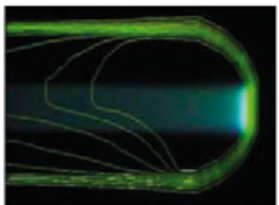

( lateral scanning

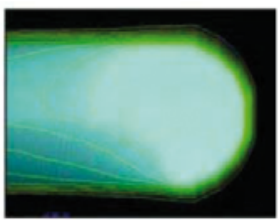

$=3 \mathrm{~d}$ conformed dose)

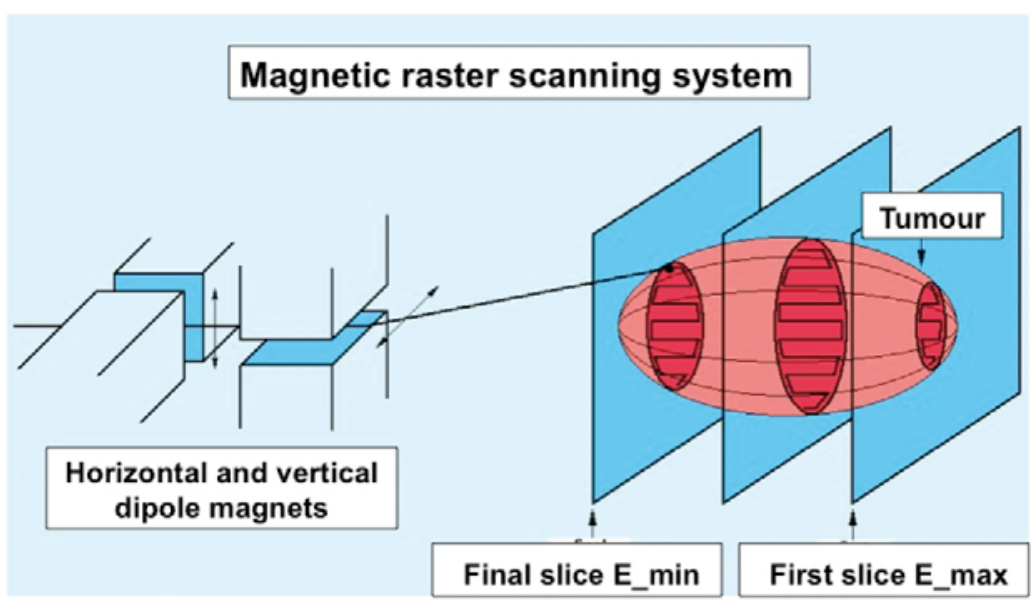

Fig. 3. Developed at PSI, the "spot scanning" technique consists in chopping the beam from a cyclotron to obtain discrete dose spots of given energy and direction which are used to form a uniform dose distribution (left). Developed at GSI, the "raster scanning" is based on the use of a pencil beam to paint continuously a slice of the tumour. The irradiation of successive slices, corresponding to different beam energies, gives a three-dimensional uniform dose distribution (right). (Courtesy of PSI and GSI.)

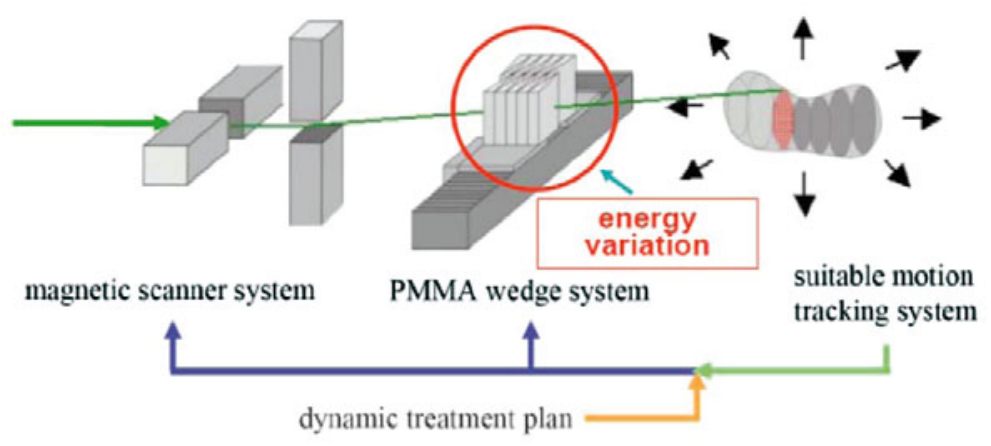

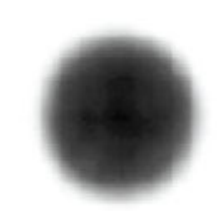

static

Sven O. Grözinger, GSI Darmstadt

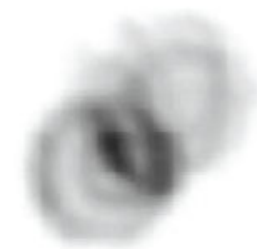

moving, non-compensated

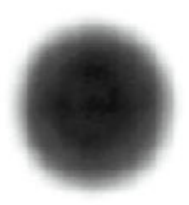

moving, compensated

Fig. 4. The feedback system — studied numerically and experimentally at GSI - compensates for the movements of the organs acting, with two bending magnets, to correct the transverse movements and, with absorbers of variable thickness, to compensate for longitudinal movements. (Courtesy GSI.)

It has to be remarked that most of the tumours treated so far by particle therapy - like for example head and neck cancers - are not subject to motion due to respiration. The treatment of moving organs, like the lung, represents an important challenge and a very actual theme of research. In Japan, a synchronization "gating" between the beam and the patient's respiration is used since long and the irradiation takes place only when the tumour is in the appropriate position [16]. More sophisticated techniques of active compensation are under study at GSI where the realisation of an on-line feedback system will allow the change of position and energy of the beam to correct for organ motion effects (fig. 4). In general, if the tumour target is "painted" only once, organ motion represents a severe inconvenience since any non-compensated movement can cause important local under-dosages or over-dosages.

Three strategies have been considered to reduce organ motion effects. In order of increasing complexity they are:

i) as mentioned above, in the irradiation of the thorax and the abdominal region the dose delivery is synchronized with the patient expiration phase (respiratory gating); 

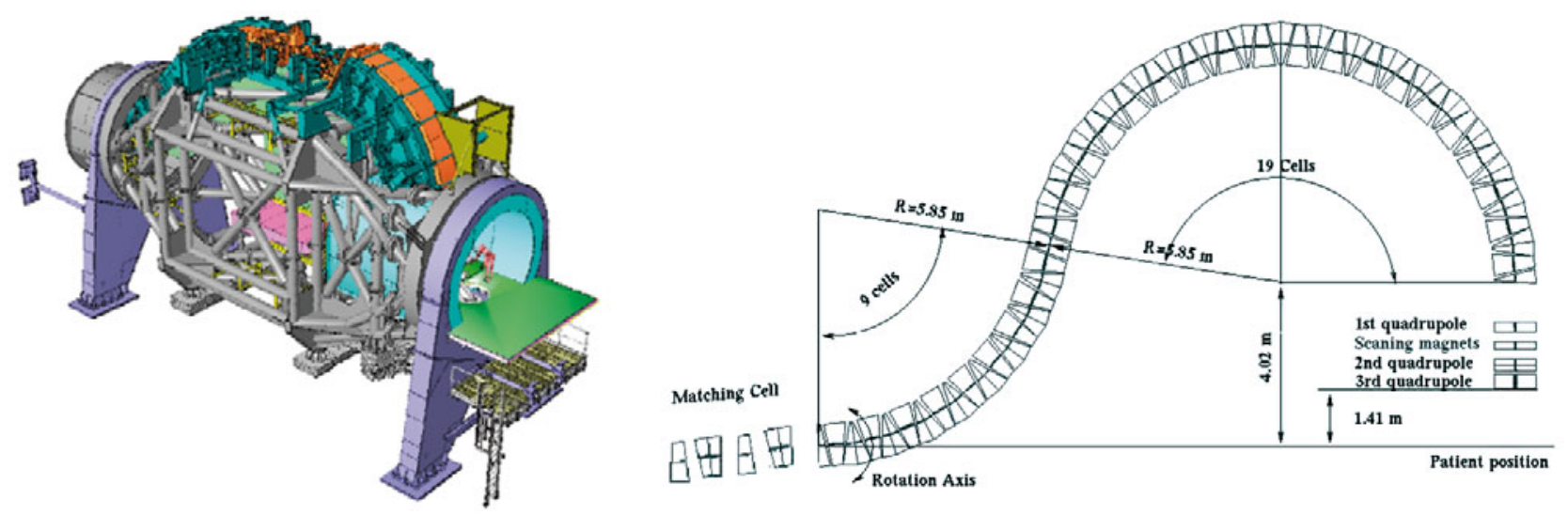

Fig. 5. The only carbon ion gantry constructed so far for the HIT centre in Heidelberg (left) and the project for a carbon/proton non-scaling FFAG isocentric gantry (right).

ii) the movement of the target is detected by a suitable system, which outputs in real-time its 3D position, and a set of feedback loops compensate for the predicted position in the dose delivery plan with on-line adjustments of the transverse and longitudinal locations;

iii) the tumour - continuously tracked as in point ii) - is painted many times in three dimensions so that not only the movements of the organs (if not too large) can be followed but also any under-dosage or over-dosage can be compensated during a following pass (multi-painting).

As far as the system which tracks the tumour target is concerned, there are various technical solutions and many others are under development, mainly in relation to conventional X ray therapy. These techniques include on-line fluoroscopy, ultrasounds, markers fixed on the body and looked at by infrared cameras [17], on-line imaging of the patient skin combined with biomechanical models of the respiration [18].

The use of Magnetic Resonance Imaging (MRI) to reduce target-positioning errors in radiation therapy is developing very fast and open magnet MRI scanners have been proposed for Image Guided Proton Therapy (IGPT) [19]. With respect to conventional MRI scanners, open magnets allow more comfort for the patient and, when used in radiation therapy, allow the terapeutical beam to reach the patient with minimal limitations. One problem of this technique is that tissue-air-bone transitions cause large magnetic field inhomogeneities. Images can be therefore distorted with severe artefacts on the guiding algorithms and, consequently, on the dose distributions. Correction procedures are under study and corrected images have been produced at a rate of $8 \mathrm{~ms}$ or less, making MRI-guided particle therapy very attractive [20].

An optimal delivery system should be based on an effective measuring device and should allow the use of any combination of the above mentioned three approaches: respiratory gating, active angular/energy feedbacks and multipainting. This is one of the most important frontiers of particle therapy [21].

\section{Challenges in ion gantries}

Due to the three times higher magnetic rigidity with respect to protons, a conventional magnet ion gantry is necessarily very big, like the one constructed at HIT (fig. 5, left). To make carbon ion gantries more compact, the use of superconductivity has been under study since some time. Recently, in the framework of the European Network for Light Ion Therapy (ENLIGHT) [22], two projects have been financed: PARTNER and ULICE. In each of them a Working Package is devoted to the study the feasibility and development of innovative lightweight rotating delivery systems, specifically optimized for a clinical environment. The aim of the work packages is to analyze the various aspects that influence the design of a carbon ion gantry and to produce a design of the device. Both medical/functional and technological issues are considered to obtain a design that controls costs without limiting significantly the functionalities.

One of the main challenges here is the depth scanning of the tumour target, which in a normal proton gantry is made by reducing the field by about $10 \mathrm{mT}$ in about $100 \mathrm{~ms}$, corresponding to about $5 \mathrm{~mm}$ on the residual range. This rapid field variation is not feasible in a superconducting magnet. Moreover, the good field region is much smaller in a superconducting magnet than in a normal one. This limits the use of scanning magnets located upstream of the $90^{\circ}$ bending magnet and favours the "downstream" solution, which in turn requires gantries of larger radii.

A few years ago a gantry based on a more "exotic" beam transport technique has been proposed: the Fixed Field Alternating Gradient (FFAG) gantry [23], shown in fig. 5. This apparatus is relatively light and is characterized by a 

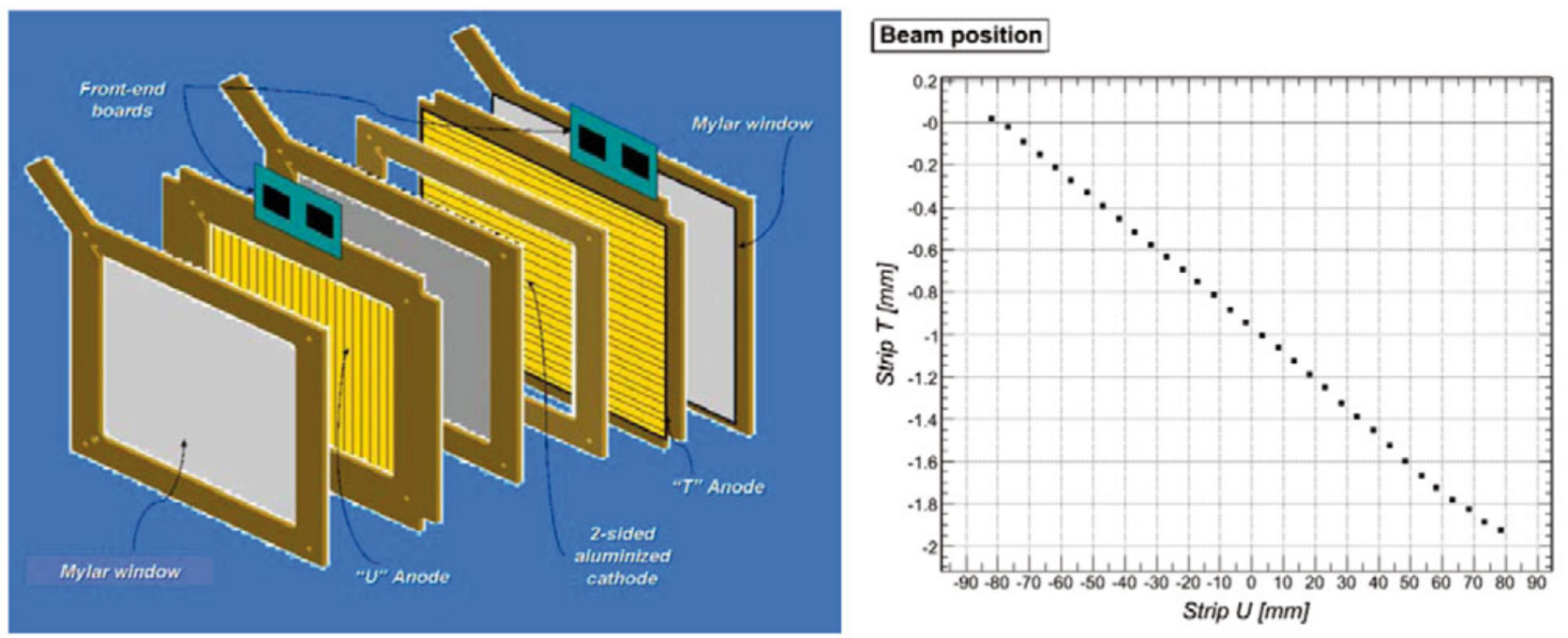

Fig. 6. SAMBA (Strip Accurate Monitor for Beam Applications) is composed by two orthogonal 2 mm strip ionization chambers (left). This detector, in use at PSI, is capable to monitor on-line the beam intensity and the transverse position with submillimetric precision during spot scanning (right).

very large momentum acceptance, which would allow good scanning capabilities. This is an important feature in the case of fast cycling accelerators, as linacs and FFAGs, in which the energy can be adjusted every few milliseconds.

\section{Challenges in imaging and quality assurance}

In modern radiation therapy imaging is essential and Computed Tomography (CT) is the basis of treatment planning. In the near future, the role of MRI and PET functional imaging will surely acquire more importance. In particular, innovative molecules [24] for PET imaging are nowadays in a phase of advanced study and will provide fundamental information for treatment planning on hypoxia and on the localization of tumours, which are almost invisible to CT [2].

On-line monitoring of the hadron beams during treatment is of paramount importance for quality assurance. Many interesting developments in the field of particle detectors have been performed in the last years, as the innovative pad ionization chambers developed for CNAO by INFN-Torino and TERA Foundation [25]. In the same framework, strip ionization chambers have been built for CPO in Orsay and for the Gantry 2 of PSI [26] (fig. 6, left). As shown in fig. 6 (right), these chambers allow on-line control of the intensity of the beam and of its position and shape with sub-millimetric precision.

In radiation therapy, the control of the dose distribution delivered to the tumour target relies on off-line dosimetry and not on direct on-line measurements. At GSI, an innovative technique [27] —in-beam PET (ibPET) — has been developed exploiting the fact that carbon ions produce ${ }^{11} \mathrm{C}$ and ${ }^{15} \mathrm{O}$ nuclei by interacting with the nuclei of the patient's body (fig. 7).

Since ${ }^{11} \mathrm{C}$ and ${ }^{15} \mathrm{O}$ are positron emitters, their distribution can be measured - by means of a PET camera installed in the treatment room - and compared with the treatment planning. Studies are underway also to exploit this technique for proton-therapy [28] and by using an ordinary PET camera with which the patient is scanned right after the treatment.

This technique produces images related to the delivered dose, but, unfortunately, is affected by three problems. Firstly, the number of the electron-positron annihilations is small (of the order of $300 \mathrm{~s}^{-1} \mathrm{~cm}^{-3}$ ), so that the patient has to remain in the treatment room few minutes after the end of the irradiation to increase the statistics. Secondly, during this time, the activity is washed out by the blood flow. Finally, the accidental rate, due to the Compton effect of the $511 \mathrm{keV}$ photons, is large. To avoid this last inconvenient, cheap detectors of large area, which can measure the time of flight with less than 100 ps time resolution (TOF-PET), are under development [29].

To overcome the disadvantage of PET methods being caused by the half-lives of the positron emitters and subsequent blood flow washout, the detection of prompt radiation components following nuclear reactions between the incoming particles of the therapeutic beam and the nuclei of the tissues represents a promising modality. Evidently, metabolic processes do not influence the spatial distribution of these components. Potentially useful radiation modalities are prompt single $\gamma$-rays, light charged particles and neutrons. Published experimental investigations indicate that the distribution of single $\gamma$-rays reflects the range distribution of the primary ions [30]. 

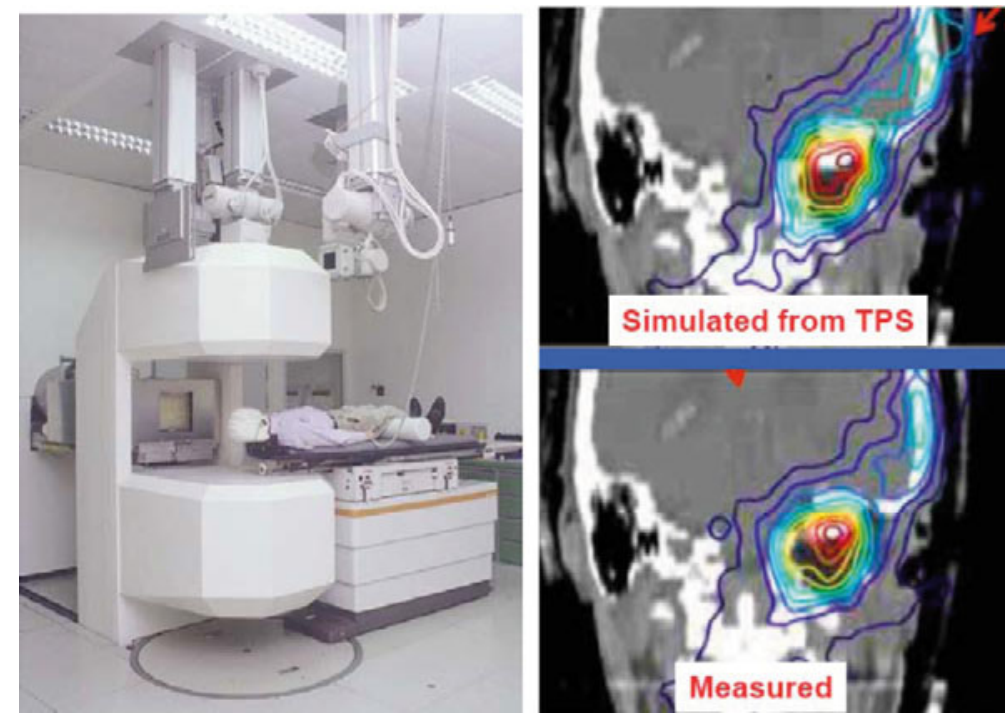

Fig. 7. The treatment room at GSI equipped with the on-beam PET detector (left). Measured and simulated data demonstrate that the dose released by carbon ions is effectively conform with respect to the treatment planning. (Courtesy GSI.)

Scintigraphy imaging of single photons is widely applied in nuclear medicine and prompt gamma radiation seems to have a good potential for in vivo therapy monitoring. However, to exploit prompt gamma radiation, novel imaging devices - not common in scintigraphy - are needed because of the broad energy spectrum of the $\gamma$-rays $(0<E \leq$ $10 \mathrm{MeV}$ ). The detection of protons or other light charged particles created via nuclear reactions is technologically less challenging. However, protons experience, in contrast with respect to high-energy photons, a high stopping power, which severely limits their possible use. In practice they can be detected only when the incoming beam is made of carbon ions [29]. All these techniques are under study in the framework of the EU funded ENVISION project [22].

\section{Proton radiography}

A crucial issue of hadrontherapy is the knowledge of the range, which directly determines the precision of the method. To completely exploit the ballistic properties of charged hadrons, the determination of the location of the Bragg peak in the patient body is essential for an optimized treatment planning, both in terms of patient positioning and of dose distribution inside the patient. Presently, the density of the electrons in the tissues is determined from the greyness of properly calibrated Computed Tomography (CT) images and then introduced in the Treatment Planning System (TPS). CT data have necessarily to be corrected to obtain proton ranges, which depend on the density of the traversed material.

An image obtained with protons traversing the patient body - the so-called proton radiography - is the best instrument to calibrate precisely the electron density obtained from CT images. Proton radiography can also be used to perform in a few seconds in situ imaging for patient positioning verification before the treatment while giving a negligible dose to the patient.

Proposed at the end of the sixties [31] as an imaging technique, proton radiography has the drawback of a poor spatial resolution due to multiple Coulomb scattering and energy straggling. For this reason and because of the need of a complex installation to produce high-energy proton beams, which can traverse the patient body, this technique was almost abandoned after the first pioneering studies in favour of other imaging techniques.

A renewed interest on proton radiography has been triggered by the present world-wide development of proton therapy centres and, following the studies performed at the Paul Scherrer Institute (PSI) [32], many projects are underway in Europe and USA, mostly based on solid state detector trackers followed by a calorimeter to assess the residual energy.

A different system consisting of a set of position-sensitive Gas Electron Multiplier (GEM) detectors and a scintillator stack read out by solid-state sensors is proposed and developed by the TERA Foundation [33]. On-line images of a PMMA phantom with holes ranging from 1 to $10 \mathrm{~mm}$ diameter and form 5 to $15 \mathrm{~mm}$ depth have been obtained (fig. 8, left).

To avoid the use of complex and expensive electronic detectors, an alternative method based on nuclear emulsion films interleaved with tissue equivalent absorbers has been recently proposed [34]. After the development and the scanning of the emulsions - which allows the reconstruction of the proton tracks - proton radiography images can 

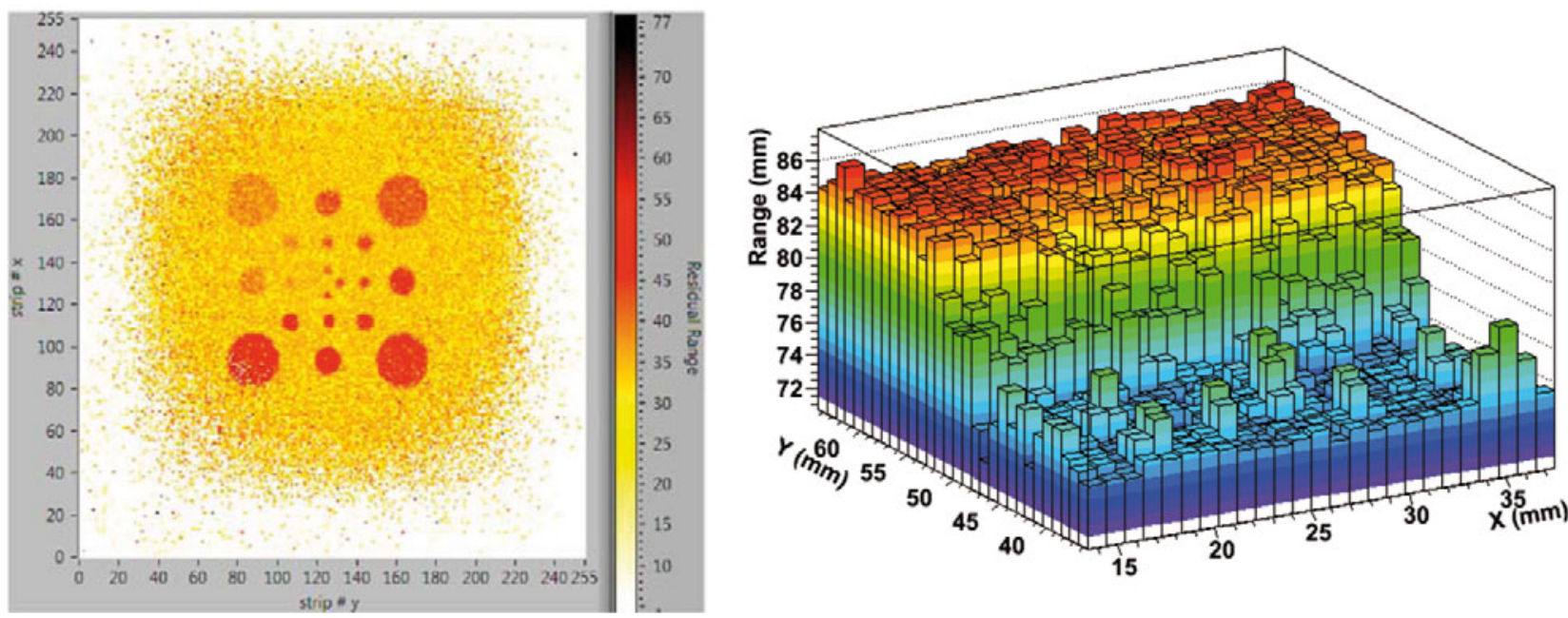

Fig. 8. Proton radiography images obtained with GEM detectors followed by a proton range detector (left) and with nuclear emulsion film detectors (right).

be obtained (fig. 8, right), with comparable resolution with respect to the other methods. This technique has the disadvantage of not producing on-line images but represents a simple and effective tool for the characterization of proton beams in the commissioning phase of proton therapy clinical facilities.

\section{Challenges in particle accelerators}

Contrary with respect to conventional radiation therapy, where each treatment room is equipped with a linac, only one radiation source is available in a hadrontherapy facility. For this reason, the choice of the particle accelerator is of paramount importance and its up-time represents a very critical issue.

At present, four commercial companies offer proton accelerators - IBA and Varian offer a normal and a superconducting cyclotron, respectively, while Hitachi and Mitsubishi offer synchrotrons. For carbon ion therapy the commercial solutions are the synchrotrons proposed by Siemens (Marburg, Kiel and Shanghai) and Mitsubishi (Hyogo, Gunma).

Cyclotrons are characterized by a beam of fixed energy which has to be degraded with passive absorbers in the first part of the beam line - in the so-called Energy Selection System (ESS) of fig. 1 - and, with respect to the human breathing cycle, present a continuous beam, advantageous for the treatment of moving organs with both feedback and multipainting.

On the other hand, the beam of a synchrotron presents a cycle — the so-called "spill" — which lasts 2-3 seconds and in which the beam is present for about 1 second. The energy can be varied from spill to spill and no movable absorbers and ESS are needed. The time structure of a synchrotron is similar to the human respiratory cycle and -in the absence of a feedback system - requires the gating of the extracted beam in coincidence with the expiratory phase when moving organs are treated.

For carbon ion therapy, the superconducting cyclotron, which is being built by IBA for the Archade project, has been designed in collaboration with the Joint Institute for Nuclear Research (JINR) in Dubna [35] and is based on the "old" $235 \mathrm{MeV}$ IBA normal cyclotron for proton therapy. ${ }^{12} \mathrm{C}^{6+}$ and other ions with a charge to mass ratio of $1 / 2$ are accelerated to $400 \mathrm{MeV} / u$ and extracted by a deflector. In particular, this machine can be used for accelerating ${ }^{4} \mathrm{He}^{2+}$, ${ }^{6} \mathrm{Li}^{3+}$ and ${ }^{10} \mathrm{~B}^{5+}$. For proton therapy, $\mathrm{H}_{2}{ }^{+}$molecules are accelerated to $260 \mathrm{MeV} / u$ and extracted by stripping. As for all cyclotrons, the energy is fixed and a 18 meter long ESS is needed to produce a clinical carbon beam in which all the produced fragments are no more present. The activation of this system and the produced secondary radiation represent a challenging issue.

In the last ten years Fixed Field Alternating Gradient accelerators (FFAGs) have been the focus of great interest because of their potentialities in the acceleration of the large currents needed for the future neutrino factories. Hadrontherapy requires nanoampere currents and a priori a FFAG does not look like the right instrument. Still many designs have been proposed because of another advantage with respect to cyclotrons and synchrotrons: the possibility of producing a high repetition rate beam having a different energy every 1-2 milliseconds, which allows a three-dimensional scanning of the target.

In Japan, a $150 \mathrm{MeV}$ proton FFAG has been built [36]. It has very wide magnets because it is of the "scaling" type, which means that during the acceleration the wiggling orbit increases in average radius but maintains the same shape. "Non scaling" FFAGs require magnets which are smaller in the radial direction but have the inconvenient that, during 


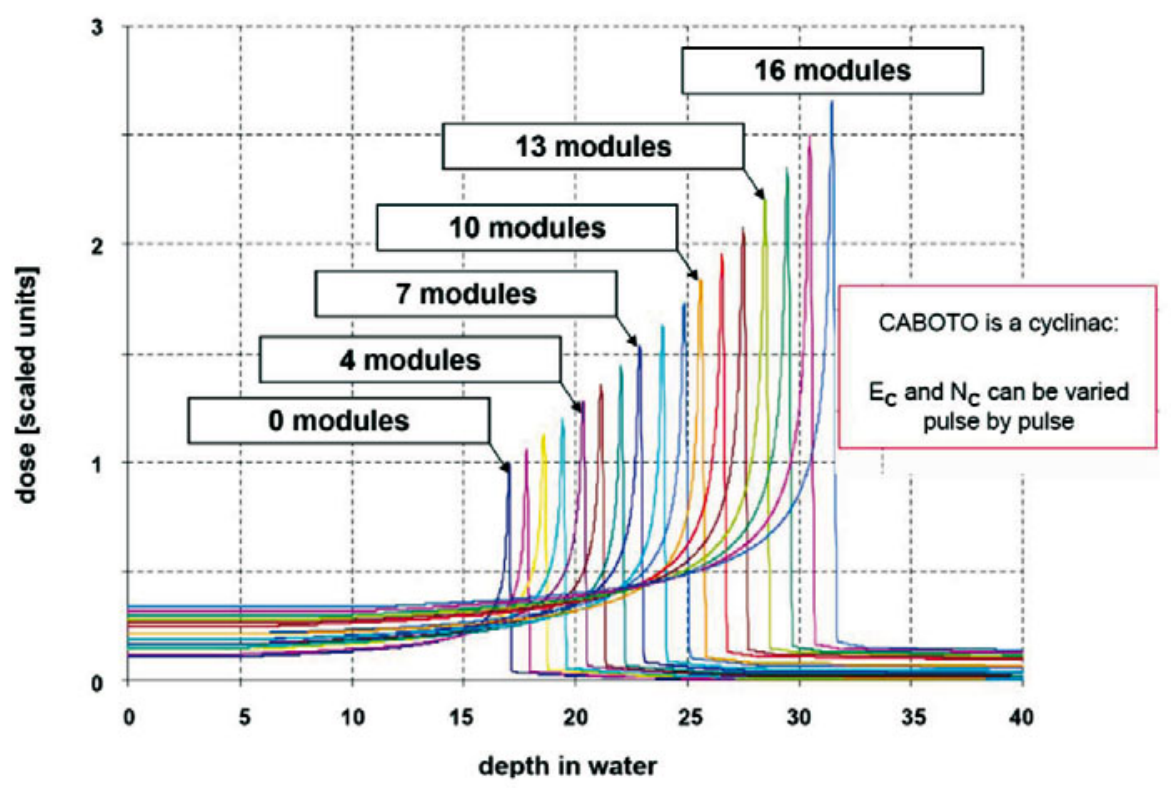

Fig. 9. The carbon ion depth dose distribution when the number of the active accelerating modules of the linac is varied one by one. To avoid superposition, a different normalization is used for each curve.

acceleration, many resonances are necessarily crossed and the beam dynamics is very delicate. An electron prototype — called EMMA - is being tested at the Daresbury Laboratory in the UK [37]. A challenging project is proposed by Keill, Sessler and Trbojevic and is based on three concentric non-scaling FFAGs. This system is surely interesting but subject to many unknowns, in particular for the injection and the extraction of the beams [38].

Injection and extraction are not a problem for linacs, which, as FFAGs, are fast cycling accelerators in which the energy of the accelerated beam can be varied continuously within a couple of milliseconds. The "cyclinac" concept, i.e. the combination of a high-frequency linac (having the standard $3 \mathrm{GHz}$ frequency) and a $30 \mathrm{MeV}$ cyclotron injector, has been proposed in 1993 by one of us (UA) [39]. A $3 \mathrm{GHz}$ standing wave 1 meter long module has been constructed and accelerated protons from 62 to $73 \mathrm{MeV}$ [40].

CABOTO (CArbon BOoster for Therapy in Oncology) is the application of the same principle to the acceleration of carbon ions to the energy of $400 \mathrm{MeV} / u$ [41]. A possible set-up consists on a $150 \mathrm{MeV} / u$ cyclotron, which accelerates $\mathrm{H}_{2}{ }^{+1}$ and $\mathrm{C}^{+6}$ ions with the linac that boosts them to the required energies with a $30 \mathrm{MV} / \mathrm{m}$ average acceleration gradient [42]. Experimental tests are under way to choose the operating frequency between $3 \mathrm{GHz}$ and $5.7 \mathrm{GHz}$. The energy can be varied from spot to spot (fig. 9) and the tumor target can be scanned in three dimensions (i.e. transversally and also along the beam direction) with a high repetition rate $(300-400 \mathrm{~Hz})$.

Figure 10 shows a dimensional comparison among the different accelerators used and/or proposed for carbon ion therapy [41].

An important remark: the psychological and economical burden for the patient and the health service can be minimized by using a carbon ion beam for a $4-5$ session "boost" to be delivered in one week before the conventional treatment, which can then be performed - together with the necessary follow-up - in the radiotherapy department close to the patient's home. As already mentioned, this radiotherapy modality is today the theme of clinical investigations on specifically selected tumours.

\section{Proton single-room facilities}

The need to reduce size, cost and complexity of hadrontherapy centres may bring a deep change of the entire discipline in the next future thanks to the development of single-room facilities.

An interesting solution based on a compact synchrotron ( $5 \mathrm{~m}$ diameter and 15 tons) with a horizontal beam sent to a single treatment room is proposed by ProTom [43].

A second line of development concerns single-room proton facilities with a rotating beam. The logic can be best appreciated by browsing table 3 [41], which has been constructed by using the results of the epidemiological studies performed in Austria, France, Italy and Germany in the framework of the EU funded network ENLIGHT [44]. They can be summarized by saying that in the medium-long term about $12 \%(3 \%)$ of the patients treated with high-energy 


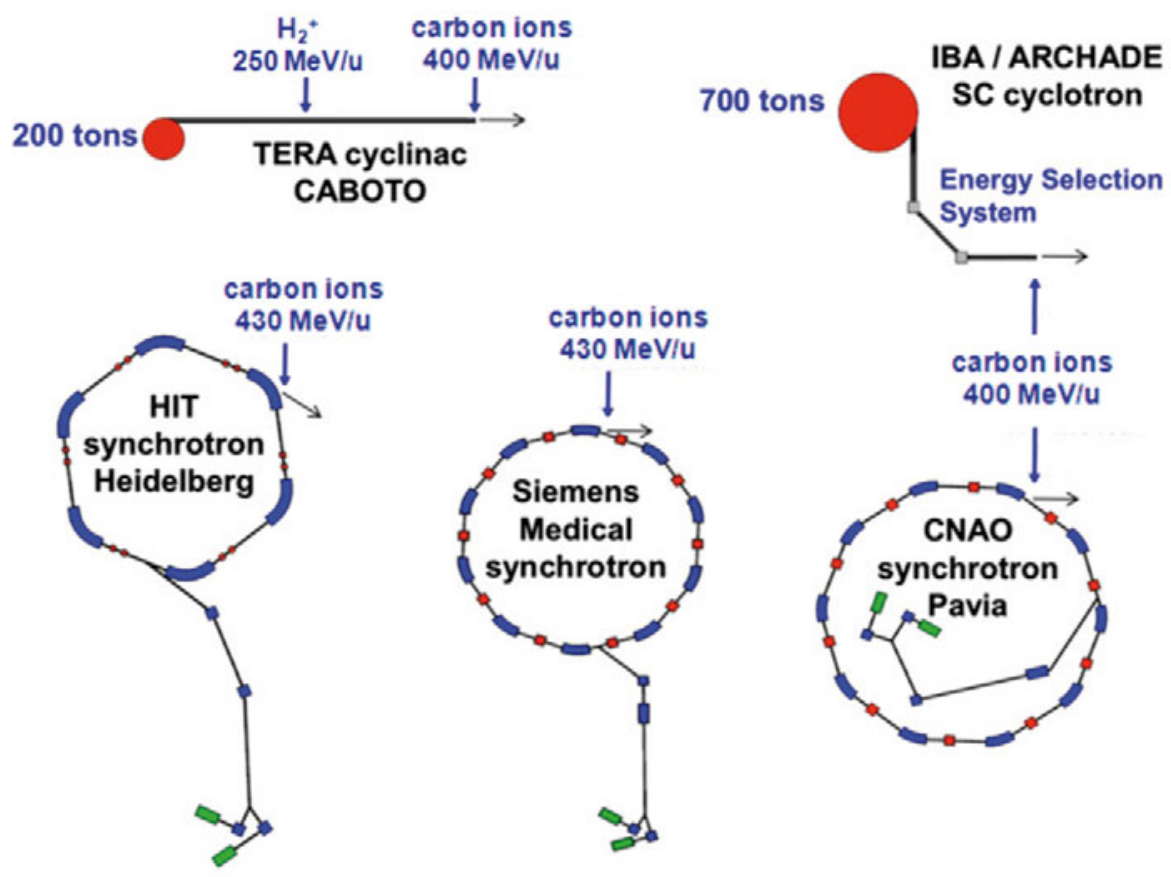

Fig. 10. Dimensional comparison of the cyclinac solution with the European carbon ion accelerators.

Table 3. Estimate of the number of X-ray and hadron treatment rooms [41].

\begin{tabular}{|c|c|c|c|c|c|c|}
\hline $\begin{array}{c}\text { Radiation } \\
\text { treatment }\end{array}$ & $\begin{array}{c}\text { Patients per } \\
\text { year in } 10^{7} \\
\text { inhabitants }\end{array}$ & $\begin{array}{c}\text { Av. } \\
\text { number of } \\
\text { sessions } \\
\text { patient }\end{array}$ & $\begin{array}{c}\text { Sessions/d } \\
\text { in } 1 \text { room } \\
(\mathrm{d}=12 \mathrm{~h})\end{array}$ & $\begin{array}{c}\text { Patients/y } \\
\text { in 1 room } \\
(\mathrm{y}=230 \mathrm{~d})\end{array}$ & $\begin{array}{c}\text { Rooms per } \\
10 \text { million } \\
\text { people }\end{array}$ & $\begin{array}{c}\text { Relative } \\
\text { ratio }\end{array}$ \\
\hline Photons & 20000 & 30 & 48 & 370 & 54 & $8^{2}$ \\
\hline Protons $(12 \%)$ & 2400 & 24 & 36 & 345 & 7.0 & 8 \\
\hline C ions $(3 \%)$ & 600 & 12 & 36 & 690 & 0.87 & 1 \\
\hline
\end{tabular}

photons would be better cured with fewer secondary effects if they could be irradiated with proton (carbon ion) beams.

The table presents the number of treatment rooms needed in five/ten years for a population of 10 million people living in a developed country. For proton therapy in the long term a more flexible and patient-friendly solution will be the one based on a single-room proton accelerator/gantry system, which is constructed on a relatively small area $\left(\leq 500 \mathrm{~m}^{2}\right)$ attached to an existing hospital building. Small (large) radiotherapy departments run 1-2 (5-6) electron linacs so that, typically, 8 conventional rooms are present in 3-4 hospitals covering a population of $1.5-2$ millions. The single-room proton facility will be attached to one of these hospitals but serve also the others.

The most advanced solution is the single-room facility under development by Still River Systems in collaboration with MIT [45]. This apparatus is based on a very compact $250 \mathrm{MeV}$ superconducting synchrocyclotron designed to fit in a single treatment room and rotate around the patient. The fixed energy output beam will be pulsed at $200 \mathrm{~Hz}$. Of course, as in the case of cyclotrons, movable absorbers are needed to adjust the proton beam energy and, since passive spreading is proposed, the dose distribution is not optimal (see fig. 2). The shielding of the patient from the neutrons produced in the close-by absorbers is a challenging problem, together with the possibility of implementing scanning pencil beams. In 2009, the 9 T niobium-tin superconducting magnet has been tested and the 15 tons synchrocyclotron assembled. The first beams have been extracted in 2010 and the company foresees the installation of the first two systems in the near future.

The company IBA is developing an innovative single room proton therapy facility named Proteus One [46]. This solution foresees a $230 \mathrm{MeV}$ superconducting synchrocyclotron with a repetition rate of $1000 \mathrm{~Hz}$ directly connected 


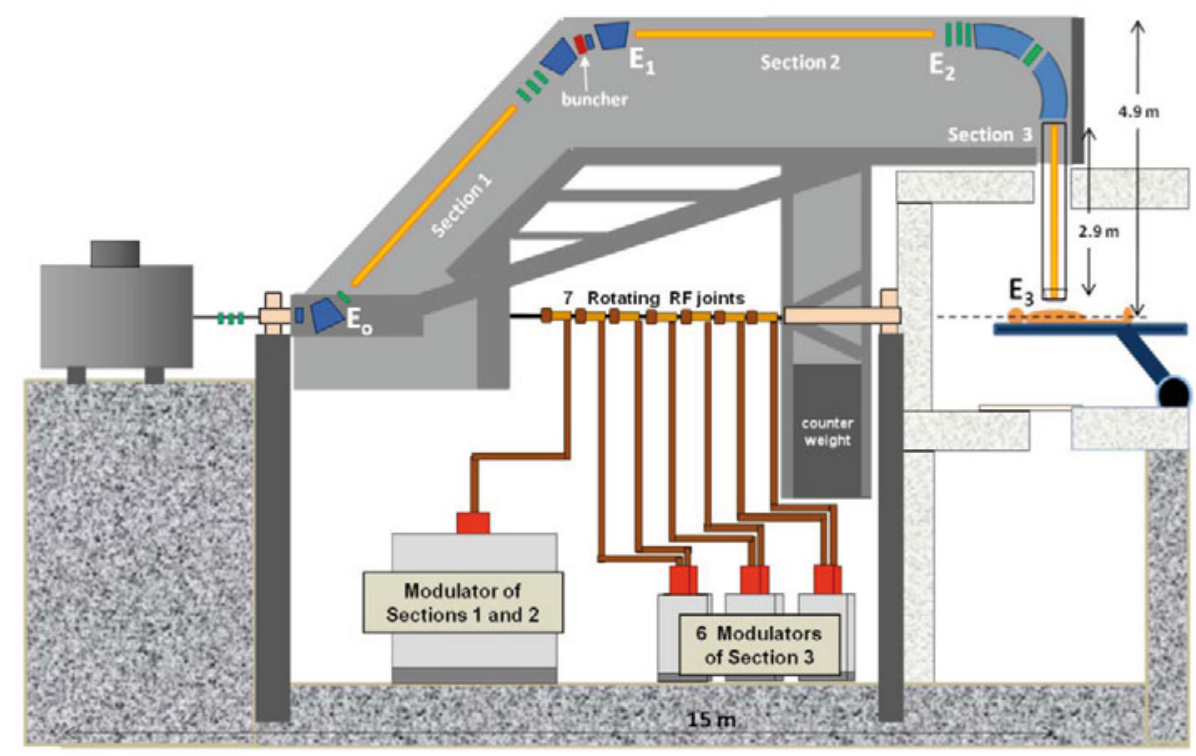

Fig. 11. TULIP (Turning LInac for Prototherapy) is a linac-based single-room proton therapy facility optimized for fast cycling spot scanning.

with a compact gantry in which the ESS is embedded. The gantry is capable of a $220^{\circ}$ rotation around the patient to allow some redundancy with respect to a $180^{\circ}$ rotation and is optimized for pencil beam scanning and multipainting.

Two further projects, which should produce proton beams rotating around the patient, are under study.

The Lawrence Livermore National Laboratory (LLNL), in collaboration with Tomotherapy and CPAC, is developing the Dielectric Wall Accelerator (DWA), which accelerates protons in a non-conducting beam tube (the dielectric wall) energized by a pulsed power system. DWA is an induction accelerator. A classical induction accelerator is made of modules, containing ferro-magnetic cores, which — powered in sequence - accelerate large currents with gradients of the order of $100 \mathrm{MV} / \mathrm{m}$ [47]. Open problems of this scheme are the focusing of the accelerated protons and the practical feasibility of a $100 \mathrm{MV} / \mathrm{m}$ gradient, which would allow having the DWA rotating around the patient in a small single-room facility.

TERA has proposed TULIP (Turning LInac for Prototherapy) as effective response to the above-discussed needs [48]. This apparatus consists on a cyclotron used as the injector of a system composed by high-frequency and high-gradient linacs mounted on a rotating structure. The version presented in fig. 11 is based on a $5.7 \mathrm{GHz}$ standing-wave linac producing a bunched beam at $50-150 \mathrm{~Hz}$ directed towards the patient while the gantry rotates and the proton energy is adjusted — from one pulse to the next, if needed - in a 110-200 MeV energy range. Making use of all the advantages of a linac [21], the dose is delivered by scanning by means of two transverse magnetic fields to an area equal to $20 \times 20 \mathrm{~cm}^{2}$. The active delivery system is similar to the one of a helical Tomotherapy, with the advantage of a much better sparing of the healthy tissues surrounding the tumour target. TULIP presents many technological challenges, such as the mechanical structure, the beam transport through different accelerating structures and the distribution of the radio-frequency $(\mathrm{RF})$ power to the rotating linacs.

Looking into the very far future, the acceleration of protons and ions by means of laser plasma devices represents a fascinating field of research. It has to be remarked that, at present, only the maximum energy of $67.5 \mathrm{MeV}$ for protons has been very recently achieved [49]. Despite the large efforts and progress in this field, protons are produced with a very wide energy spread peaked at low energies, making of the dose distribution system a very difficult challenge [50].

\section{Outlook}

Since its beginnings, nuclear and particle physics have offered medicine and biology tools and techniques to study, detect and cure cancer. Hadrontherapy represents today their major contribution to the cure of patients and many interesting developments, at the forefront of science and technology, are in progress. Further challenging innovations are appearing at the horizon, assuring a very exciting time to the future of this discipline. 


\section{References}

1. U. Amaldi, G. Kraft, Rep. Prog. Phys. 68, 1861 (2005).

2. U. Nestle et al., Phys. Med. Biol. 54, R1 (2009).

3. R.R. Wilson, Radiology 47, 487 (1946).

4. J.R. Castro, Heavy ion therapy: the BEVALAC epoch, in Hadrontherapy in Oncology, edited by U. Amaldi, B. Larsson (Elsevier, 1994) pp. 208-216.

5. A. Brahme, Int. J. Radiat. Oncol. Biol. Phys. 58, 603 (2004).

6. A. Tobias et al., Cancer Res. 18, 121 (1958).

7. R. Wilson, A Brief History of the Harvard University Cyclotrons (Cambridge University Press, 2004).

8. G. Coutrakon et al., Med. Phys. 21, 1691 (1994).

9. A.M. Koehler, LBL Pub 22962, 1987.

10. Particle Therapy CoOperative Group (PTCOG), ptcog. web.psi.ch.

11. R. Miralbell et al., Int. J. Radiat. Oncol. Biol. Phys. 54, 824 (2002).

12. L. Badano et al., Proton-Ion Medical Machine Study (PIMMS), Part I, CERN/PS 1999-010 DI, 1999 and Part II, CERN/PS 2000-007 DR, 2000.

13. E. Pedroni et al., Med. Phys. 22, 37 (1995).

14. T. Haberer et al., Nucl. Instrum. Methods A 330, 296 (1993).

15. E. Pedroni et al., Z. Med. Phys. 14, 25 (2004).

16. S. Minohara et al., Int. J. Radiat. Oncol. Biol. Phys. 47, 1097 (2000).

17. G. Baroni et al., J. Radiat. Res. 48, A61 (2007).

18. J. Saadé et al., A preliminary study for a biomechanical model of the respiratory system, Engineering and Computational Sciences for Medical Imaging in Oncology, ECSMIO 2010, Angers (France), 2010; available at http://hal.inria.fr/hal-00509817/en.

19. B.W. Raaymakers et al., Phys. Med. Biol. 53, 5615 (2008).

20. S.P.M. Crijns et al., Phys. Med. Biol. 56, 289 (2011).

21. U. Amaldi, S. Braccini, P. Puggioni, High Frequency Linacs for Hadrontherapy, in Reviews of Accelerator Science and Technology, Vol. II (RAST2) (World Scientific, 2009) pp. 111-131.

22. European Network for Light Ion HadronTherapy (ENLIGHT), enlight.web.cern.ch.

23. D. Trbojevic et al., Update on the innovative Carbon/Proton non-scaling FFAG isocentric gantries for cancer therapy, Proceedings of IPAC10, Kyoto (Japan) (2010), p. 124; available at http://epaper.kek.jp/IPAC10/index.htm.

24. R. Nutt et al., Clin. Pharmacol. Ther. 81, 792 (2007).

25. S. Braccini et al., MATRIX: an innovative pixel ionization chamber for on-line beam monitoring in hadrontherapy, Advanced Technology and Particle Physics (World Scientific, 2006) p. 677.

26. S. Braccini, An Innovative Strip Ionization Chamber for on-line Monitoring of Hadron Beams, presented at PTCOG 44, Zurich (Switzerland) 2006, p. 44; available at http://www.ptcog.com.

27. W. Enghardt et al., Nucl. Instrum. Methods A 525, 284 (2004).

28. K. Parodi et al., IEEE Trans. Nucl. Sci. 52, 778 (2005).

29. F. Sauli, AQUA - Advanced Quality Assurance for CNAO, presented at the ICPT Workshop, Oxford, September 2008; available at http://www.basroc.org.uk/basroc_files/icpt/ESFWorkshop230908/ESF08_programme.htm.

30. E. Testa et al., Nucl. Instrum. Methods B 267, 993 (2009).

31. A.M. Koehler, Science 160 (1968).

32. P. Pemler et al., Nucl. Instrum. Methods A 432 (1999).

33. U. Amaldi et al., Nucl. Instrum. Methods A 629, 337 (2011).

34. S. Braccini et al., J. Instrum. JINST (5) P09001 (2010).

35. Y. Jongen et al., Design studies of the compact superconducting cyclotron for hadron therapy, in Proceedings EPAC06 (2006), pp. 1678-1680; available at http://accelconf.web.cern.ch/AccelConf/e06/.

36. M. Tanigaki et al., Nucl. Instrum. Methods A 612, 354 (2010).

37. R. Barlow et al., Nucl. Instrum. Methods A 624, 1 (2010).

38. E. Keil, A.M. Sessler, D. Trbojevic, Phys. Rev. ST AB 10, 54701 (2007).

39. U. Amaldi, The Italian hadrontherapy project, in Hadrontherapy in Oncology, edited by U. Amaldi, B. Larsson (Elsevier, 1994) p. 45.

40. U. Amaldi et al., Nucl. Instrum. Methods A 521, 512 (2004).

41. U. Amaldi et al., Nucl. Instrum. Methods A 620, 563 (2010).

42. A. Garonna et al., Cyclinac Medical Accelerators Using Pulsed C6+/H2+ Ion Sources, arXiv:1007.0352, August 2010.

43. www protominternational.com.

44. M. Dosanjh et al., Nucl. Instrum. Methods Phys. Res. A 571, 191 (2007).

45. www. stillriversystems. com.

46. IBA, private communication and ww. iba-worldwide.com.

47. G.J. Caporaso, Y.-J. Chen, S.E. Sampayan, The dielectric wall accelerator, in Reviews of Accelerator Science and Technology, Vol. II (RAST2) (World Scientific, 2009) pp. 253-263.

48. U. Amaldi, S. Braccini, G. Magrin, P. Pearce, R. Zennaro, Ion acceleration system for medical and/or other applications, PCT/IT2006/000879, patent WO 2008/081480 A1 and US2010/0320403 A1.

49. T. Kluge et al., presented at the 52nd Annual Meeting of the American Physics Society, Chicago, November 2010; available at http://meetings.aps.org/Meeting/DPP10/Event/135039.

50. U. Amaldi, S. Braccini, Present and Future of Hadrontherapy, Superstrong Fields in Plasmas (American Institute of Physics, 2006) p. 248. 